\title{
Nephrology, renal medicine, kidney doctors: is the discussion about the name of the rose much ado about nothing?
}

\author{
Giorgina Barbara Piccoli ${ }^{1}$
}

Accepted: 2 March 2021 / Published online: 15 May 2021

(c) Italian Society of Nephrology 2021

In a brilliant point of view paper, a large, heterogeneous group of expert nephrologists contested one of the proposals of the new nomenclature proposed by KDIGO, that was published recently, first by Kidney International and then by several other specialized journals including our own [1, 2]. A similar shorter commentary was recently published in Kidney International [3].

The paper was submitted to our journal at a time when the second COVID-19 wave was challenging our resilience, and my first reaction to the Shakespearean citation was to label it "much ado about nothing".

In fact, when the nomenclature paper was first published, some of us chuckled at the idea of calling our journal "The Journal of Kidneylogy" and some joked that having three words (renal, kidney, nephrology) to choose from, allowed the increasing number of nephrology (renal medicine/kidney medicine) journals to at least have different titles names.

The call to preserve "renal" and "nephro" in the glossary of kidney health and disease is not trivial, however. While the authors may make us smile by stretching the idea of systematically preferring words of Anglo-Saxon origin, suggesting for instance that "peritoneal dialysis" could be replaced in medical writing with "belly-wall membrane blood purification", they also make us reflect on what language is and does, in particular the English we use in medicine.

In medicine, we read in English, we write in English, we communicate in English, but for very few of us it is our first language, our mother tongue. On more than one occasion we all have heard jokes about the fact that non-native speakers' "broken English" has become the official congress language, and for many of my generation using this language

Giorgina Barbara Piccoli

gbpiccoli@yahoo.it

1 Nephrologie, Centre Hospitalier Le Mans, Avenue Roubillard 194, 72000 Le Mans, France correctly was even more of a challenge than putting together our first multivariate analysis.

The result of these arduous efforts is a shared medical language that enables us to communicate, but is often poor or oversimplifies our ideas. In fact, on a few occasions, my team and I received negative comments about a "flowery" or "unscientific" presentation because the cultivated American-born lady who reviews our papers tried to transform our mistakes, Latinisms, and convoluted constructions into something readable, but not devoid of elegance.

When, almost simultaneously in Europe, English became the common medical language, and "the web" gave us access to abstracts of papers from a growing number of journals in real time, allowing us to abandon our late evening searches in dusty libraries, we were all urged to learn, if not to speak, at least to read English. In the same period, Kidney International, which had initially published its abstracts in both English and French, unsurprisingly became an English only journal.

Attitudes towards language change, and it is through trial and error that languages evolve, not only in medicine. The first common language in the western world, Latin, progressively diverged and developed into what are now known as the Romance languages. No language is exempt from this dynamic balance between converging into an often rigid and impoverished common language and diverging into lively and colorful new ones. The Word software programs currently available propose UK, US and Australian English; Canadian French is not spoken in Paris. The same complexity certainly holds true for Mandarin and Arabic.

In his Nobel Prize talk the poet Derek Walcott spoke about languages, and how living things became words, and words living things: "All of the Antilles, every island, is an effort of memory; every mind, every racial biography culminating in amnesia and fog. Pieces of sunlight through the fog and sudden rainbows, arcs-en-ciel. That is the effort, the labour of the Antillean imagination, rebuilding its gods from bamboo frames, phrase by phrase." And in the banquet 
speech the relationship between changing words and living things is mentioned again "The honour that you pay me is accepted in the one name that comprises all of the supposedly broken languages of the Caribbean. They cohere in this moment, a moment that recognises their endeavour and one which I receive with pride and humility on their behalf. Pride in the continuing struggle of Antillean writers..." [4].

What we are discussing is whether the word kidney, which is of Anglo-Saxon origin, should systematically replace renal and nephron, which are derived from Latin and Greek, in an approach centered on western culture. Our discussion of this issue has often failed to take into account the importance of the multifaceted Arabic language and the emerging role of the new generations of Asian scholars. Just one step behind the growing number of web-savvy physicians is a growing number of struggling patients who, either by relying on their own knowledge, or turning to Google Translate or Lexicool for help, try to understand how they can best care for their health. Depending on what their native language is, some of them will find kidney more intuitive, while for others it will be renal or nephron. And these are just three words in the medical jargon jungle. Favoring one of them, possibly with the unexpected consequences highlighted in this paper, will not make it any easier to understand what kidneys do, how they work, and how we can try to cure renal diseases.

There are things that are not said, and things that can be read in several ways, even when the same words are used. Balancing the need to define diseases in a uniform way with the risk of impoverishing the language or unwittingly taking into consideration the needs of only one part of the multiethnic, multifaceted world that uses the same common language, is far from simple.

The point of view paper openly acknowledges the importance of the KDIGO guidelines and of the recent efforts to create a common nomenclature, even though it contests the "name of the rose". Interestingly, the authors of the viewpoint do not disagree with other key suggestions, such as abandoning the ESRD or ESKD acronyms (previously popular because of the wording used in the law funding maintenance dialysis) in favor of kidney failure, a wording definitely clearer when speaking with patients.

Diseases need clear definitions, but things may have different names.
I sincerly hope that this message will not be trivialized into an attack against the global guidelines which we now have in nephrology (kidney medicine/renal medicine).

I hope, all the more so given the troubled times we live in, that this paper will make us reflect on how much we need to understand our roots if we are to maintain our identity.

And that language plays a vital role in this process.

Acknowledgments To Susan Ruff for her help in reviewing this paper.

Funding None.

\section{Declarations}

Conflict of interest None.

Ethical permissions-other ethical issues None.

\section{References}

1. Kalantar-Zadeh K, McCullough PA, Agarwal SK et al (2021) Nomenclature in nephrology: preserving 'renal' and 'nephro' in the glossary of kidney health and disease. J Nephrol. https://doi. org/10.1007/s40620-021-01011-3

2. Levey AS, Eckardt KU, Dorman NM, Christiansen SL, Hoorn EJ, Ingelfinger JR, Inker LA, Levin A, Mehrotra R, Palevsky PM, Perazella MA, Tong A, Allison SJ, Bockenhauer D, Briggs JP, Bromberg JS, Davenport A, Feldman HI, Fouque D, Gansevoort RT, Gill JS, Greene EL, Hemmelgarn BR, Kretzler M, Lambie M, Lane PH, Laycock J, Leventhal SE, Mittelman M, Morrissey P, Ostermann M, Rees L, Ronco P, Schaefer F, St Clair Russell J, Vinck C, Walsh SB, Weiner DE, Cheung M, Jadoul M, Winkelmayer WC (2020) Nomenclature for kidney function and disease: report of a Kidney Disease: Improving Global Outcomes (KDIGO) Consensus Conference. Kidney Int 97(6):1117-1129. https://doi.org/10.1016/j.kint.2020.02.010

3. Bover J, Haarhaus ML, Furlano M, Ureña P, Vervloet M, daSilva I, Brandenburg V, García-Maset R, Bellasi A, Tesař V (2020) English-Latin nomenclature conundrum: should we use kidneylogy, kidneylogist? Kidney Int 98(5):1352-1353

4. https://www.nobelprize.org/prizes/literature/1992/walcott/speech/. Last accessed 21/02/2021

Publisher's Note Springer Nature remains neutral with regard to jurisdictional claims in published maps and institutional affiliations. 